\title{
Diaschisis: An Old Concept Brought to New Life
}

\author{
R. Michelle Saré \\ Section of Neuroadaptation and Protein Metabolism, National Institute of Mental Health, Bethesda, Maryland 20892 \\ Review of Ishii, Kubo et al.
}

Diaschisis, a Greek term meaning "split throughout," was introduced to neurology in 1914 by Monakow. This concept suggests that damage in one focal area of the brain can affect distant brain regions. Diaschisis was originally described in patients with ipsilateral paralysis following focal brain lesions (Finger et al., 2004). With the advent of brain imaging techniques, we now know that focal damage can result in large connectivity abnormalities in the brain (for review, see Carrera and Tononi, 2014). Traditionally, the concept of diaschisis was applied to acute brain injuries, as seen in head trauma or stroke. However, a similar phenomenon may occur in developmental disorders, as illustrated in recent work published in The Journal of Neuroscience (Ishii, Kubo et al., 2015).

Ishii, Kubo et al. (2015) used in utero electroporation in mice to ectopically express genes related to neuronal migration, inducing the formation of focal neuronal heterotopias (focal areas of ectopic tissue) (Ishii, Kubo et al., 2015). The presence of these heterotopias persisted long after birth. Although these heterotopias were

Received Nov. 6, 2015; revised Dec. 3, 2015; accepted Dec. 8, 2015.

I thank Dr. Carolyn Beebe Smith for her assistance in revising this manuscript and her suggestions regarding this manuscript.

This work was not written as part of R. Michelle Saré's official duties. The views expressed in this article do not necessarily represent the views of the NIMH, NIH, HHS, or the United States Government.

The author declares no competing financial interests.

Correspondence should be addressed to Dr R. Michelle Saré, Section of Neuroadaptation and Protein Metabolism, National Institute of Mental Health, Building 10, Room 2D54, 10 Center Drive, Bethesda, MD 20892. E-mail: Rachel.Sare@nih.gov.

DOI:10.1523/JNEUROSCI.4014-15.2016

Copyright $\odot 2016$ the authors $\quad 0270-6474 / 16 / 361051-02 \$ 15.00 / 0$ located in the somatosensory cortex, their presence resulted in early gene activation in the medial prefrontal cortex (mPFC) and in disruption of behavior associated with the mPFC. No direct connections were found between the somatosensory cortex and the mPFC, suggesting that dysregulation in the $\mathrm{mPFC}$ may have been the result of disrupted circuitry, reminiscent of diaschisis.

Furthermore, even though the lesion was isolated to a relatively small region of the somatosensory cortex, Ishii, Kubo et al. (2015) found that the animals had decreased threshold for seizure induction as well as deficits in spatial memory and decreased social dominance, both features associated with the prefrontal cortex. When the abnormal cells in the somatosensory cortex were stimulated through DREADD (designer receptor exclusively activated by designer drug) technology, the overt behavioral differences were rescued.

The authors indicate that their results are important for understanding the neurological and behavioral aspects of individuals with distinct heterotopias, which are associated in the patient population with increased seizure susceptibility and cognitive dysfunction. However, the results obtained from their study have the potential to be even more widespread in their applicability and may demonstrate how mutations in a few neurons, or a small area of the brain, can lead to widespread cognitive dysfunction.

One disorder, for which this knowledge may be particularly applicable is tuberous sclerosis complex (TSC). TSC is caused by heterozygous mutations in
TSC1 or TSC2 and is marked by a high incidence of benign tumor growths in various organ systems, including the brain, liver, and kidney. These tumor growths are postulated to develop as a result of somatic loss of function in the second allele of either TSC1 or TSC2, resulting in complete loss of function of the gene product, a phenomenon called loss of heterozygosity (LOH). LOH has consistently been demonstrated in kidney tumors (Henske et al., 1996, 1997). The other hallmark of TSC is a constellation of neurological symptoms, including cortical and cerebellar tuber formation, seizures, intellectual disability, and autism.

The cause of brain involvement in TSC is an active area of research. Although the $\mathrm{LOH}$ model is the prevailing model for the peripheral pathogenesis of TSC, $\mathrm{LOH}$ has not been detected in the brains of most patients with TSC (Henske et al., 1996). This suggests that either an alternate mechanism is responsible for brain/neurological manifestations of the disorder, or that $\mathrm{LOH}$ events in the brain of patients are present at too low of a frequency to reliably detect.

Extrapolating from the results presented by Ishii, Kubo et al. (2015), circuitry changes arising from the presence of isolated $\mathrm{LOH}$ events may profoundly impact distant brain areas, leading to seizure formation and cognitive dysfunction. If only a few distinct cells in the brain develop LOH, it would be nearly impossible to detect by current sequencing techniques, but may still yield broad circuitry changes in remote brain regions and be the cause of the behavioral mani- 
festations and seizures observed in TSC. Results from experiments in mice are consistent with this hypothesis. Electroporation has been used to sporadically knock-out Tsc1 and achieve LOH of Tsc1 in isolated cells in the brain (Feliciano et al., 2011). The resulting mice have a small circumscribed lesion that produces a neurological phenotype, i.e., increased seizure susceptibility.

The studies by Feliciano et al. (2011) and Ishii, Kubo et al. (2015) lay the groundwork for understanding the potential of focal abnormalities to cause widespread neuropathology. They point to the need for further study of isolated LOH events in the context of TSC as well as widespread effects found in other neurological disorders characterized by migration abnormalities. In addition, they demonstrate that studying isolated affected brain regions may not be sufficient for understanding neurological disorders. The circuit as a whole must be considered, with the knowledge that discrete brain abnormalities may yield dysfunction in more distant brain regions.

\section{References}

Carrera E, Tononi G (2014) Diaschisis: past, present, future. Brain 137:2408-2422. CrossRef Medline

Feliciano DM, Su T, Lopez J, Platel JC, Bordey A (2011) Single-cell Tscl knockout during corticogenesis generates tuber-like lesions and reduces seizure threshold in mice. J Clin Invest 121:1596-1607. CrossRef Medline

Finger S, Koehler PJ, Jagella C (2004) The Monakow concept of diaschisis: origins and perspectives. Arch Neurol 61:283-288. CrossRef Medline
Henske EP, Scheithauer BW, Short MP, Wollmann R, Nahmias J, Hornigold N, van Slegtenhorst M, Welsh CT, Kwiatkowski DJ (1996) Allelic loss is frequent in tuberous sclerosis kidney lesions but rare in brain lesions. Am J Hum Genet 59:400 - 406. Medline

Henske EP, Wessner LL, Golden J, Scheithauer BW, Vortmeyer AO, Zhuang Z, Klein-Szanto AJ, Kwiatkowski DJ, Yeung RS (1997) Loss of tuberin in both subependymal giant cell astrocytomas and angiomyolipomas supports a two-hit model for the pathogenesis of tuberous sclerosis tumors. Am J Pathol 151:16391647. Medline

Ishii K, Kubo K, Endo T, Yoshida K, Benner S, Ito $\mathrm{Y}$, Aizawa $\mathrm{H}$, Aramaki $\mathrm{M}$, Yamanaka A, Tanaka K, Takata N, Tanaka KF, Mimura M, Tohyama C, Kakeyama M, Nakajima K (2015) Neuronal heterotopias affect the activities of distant brain areas and lead to behavioral deficits. J Neurosci 35:12432-12445. CrossRef Medline 